\title{
To Tell the Truth
}

\section{Ethical and Practical Issues in Disclosing Medical Mistakes to Patients}

\author{
Albert W. Wu, MD, MPH, Thomas A. Cavanaugh, PhD, Stephen J. McPhee, MD, \\ Bernard Lo, MD, Guy P. Micco, MD
}

\begin{abstract}
While moonlighting in an emergency room, a resident physician evaluated a 35-year-old woman who was 6 months pregnant and complaining of a headache. The physician diagnosed a "mixed tension/sinus headache." The patient returned to the ER 3 days later with an intracerebral bleed, presumably related to eclampsia, and died.
\end{abstract}

E rrare humanum est: "to err is human." In medical practice, mistakes are common, expected, and understandable. $^{1,2}$ Virtually all practicing physicians have made mistakes, but physicians often do not tell patients or families about them. ${ }^{3,4}$ Even when a definite mistake results in a serious injury, the patient often is not told. In one study, house officers reported telling their attending physicians about serious medical mistakes only half the time, and telling the patients or families in less than a quarter of cases. ${ }^{3}$ Highly publicized cases of fatal mistakes have heightened public and professional concerns about how physicians and hospitals respond to serious mistakes. When mistakes are not acknowledged in a timely manner, there may be a perception of a cover-up, and public confidence in physicians may be undermined.

The American Medical Association's (AMA's) Principles of Medical Ethics (1957) states that a physician must report an accident, injury, or bad result stemming from his or her treatment. ${ }^{5}$ However, many physicians interpret these requirements to mean that they should report to their superiors or to the hospital quality assurance or

Received from the Department of Health Policy and Management School of Hygiene and Public Health, and the Division of Internal Medicine, Department of Medicine, Johns Hopkins University, Baltimore, Md. (AWW); the Department of Philosophy, University of San Francisco, Calif. (TAC); and the Division of General Internal Medicine, Department of Medicine, University of California, San Francisco (SJM, BL, GPM).

Presented in part at "Examining Errors in Health Care: Developing a Prevention, Education and Research Agenda," October 13-15, 1996, Rancho Mirage, Calif.

Address correspondence and reprint requests to Dr. Wu: Health Services Research and Development Center, 624 North Broadway, Baltimore, MD 21205. risk management committee, rather than to the patient. More recently, the American College of Physicians Ethics Manual states, "physicians should disclose to patients information about procedural and judgment errors made in the course of care, if such information significantly affects the care of the patient." 6 The AMA's Council on Ethical and Judicial Affairs states, "Situations occasionally occur in which a patient suffers significant medical complications that may have resulted from the physician's mistake or judgment. In these situations, the physician is ethically required to inform the patient of all facts necessary to ensure understanding of what has occurred." 7

In this article, we analyze the various ethical arguments for and against disclosing serious mistakes to patients. We also provide practical suggestions for how to discuss the sensitive topic of mistakes with patients.

\section{WHAT IS A MISTAKE?}

We define a medical mistake as a commission or an omission with potentially negative consequences for the patient that would have been judged wrong by skilled and knowledgeable peers at the time it occurred, independent of whether there were any negative consequences. This definition excludes the natural history of disease that does not respond to treatment and the foreseeable complications of a correctly performed procedure, as well as cases in which there is reasonable disagreement over whether a mistake occurred.

We categorize errors according to their genesis. System errors, also referred to as latent errors, ${ }^{2}$ derive primarily from flaws inherent in the system of medical practice. In such errors, the system "sets up" individuals to make mistakes, i.e., through the unavailability of medical records, by confusing labeling of medications, and the like. When a system error occurs, the physician shares responsibility with other elements of the health care delivery system.

Conversely, individual errors are those deriving primarily from deficiencies in the physician's own knowledge, skill, or attentiveness. For instance, a physician mistakenly prescribed a nonsteroidal anti-inflammatory agent to a patient with renal insufficiency, resulting in permanently worsened renal failure. ${ }^{3}$ In such a case of individual error, the physician has primary responsibility. 
The considerations in the disclosure of latent errors differ from those in the disclosure of individual errors. For example, in a latent error, the physician is often one link in a chain of causes generating the error. Accordingly, the disclosure of such an error may not be the sole responsibility of the physician. In what follows, we consider only the arguments for a physician to disclose his or her individual error to a patient. We also restrict ourselves to mistakes that cause significant harm, without regard to their detectability.

Errors causing harm can be subdivided into cases that are not medically remediable and those that are medically remediable. We argue that the physician has an obligation to disclose mistakes that cause significant harm, which in the judgment of a risk manager or malpractice insurer is likely to be remediable, mitigable, or compensable. Only in rare cases would a physician be permitted not to disclose a mistake causing harm to the patient. Specifically, physicians might be permitted not to tell if they have good reason to believe that disclosure would undermine the patient's autonomy in some way (e.g., incapacitate the already severely depressed patient). Or the patient might have told the doctor explicitly, "Doctor, if anything goes wrong, I don't want to know about it."

Two ethical theories assist in thinking about the disclosing of a mistake: consequentialism and deontology. A consequentialist ethical theory holds that one ought to do that act which will realize the best overall consequences. A deontological theory maintains that one ought to do that act by which one fulfills one's duties or obligations. Both consequentialist and deontological theories ground arguments for disclosure. In what follows, we first consider arguments based on consequences; then, we attend to arguments based on a physician's duties.

\section{POTENTIAL BENEFITS AND HARMS OF DISCLOSURE}

\section{Potential Benefits of Disclosure to the Patient}

The patient could benefit in many ways from knowing that a mistake had occurred. Such knowledge would allow the patient to obtain timely and appropriate treatment to correct problems resulting from the mistake. Disclosure therefore can prevent further harm to the patient. In some situations, close monitoring or a medical procedure may be necessary to mitigate the consequences of a mistake. Patients may be unwilling to permit or cooperate with necessary measures if they are unaware of the reason for doing so. ${ }^{8}$ When further treatment is indicated, disclosure is essential for informed consent. Otherwise, the uninformed patient is placed at risk of subsequent misdiagnosis and improper or inadequate treatment.

Disclosure of a mistake may also prevent the patient from worrying needlessly about the etiology of a medical problem. For example, a patient who was prescribed too much warfarin resulting in excessive anticoagulation suf- fered a gastrointestinal bleed. Telling patients about such mistakes may resolve their uncertainty about the cause of their condition, possibly allowing them to feel better by explaining that recurrence would be unlikely.

Disclosure of a mistake also provides patients with information needed to make informed decisions. Patients may develop more realistic expectations about their doctors' interventions. ${ }^{9}$ Acknowledgment of fallibility brings uncertainties into the open, reduces the possibility of misunderstandings, and encourages the patient to take greater responsibility for his or her own care.

In the case of an injury, knowing about a mistake may allow the patient to obtain compensation for lost earnings or to pay for care necessitated by the injury, ${ }^{8}$ or to at least get a bill written off. Such compensation might be obtained through settlement rather than lawsuit; under the current system, obtaining such compensation would be difficult or impossible without disclosure of the mistake.

Finally, disclosure of a mistake can promote trust in physicians. Patients have a presumption of truth-telling. ${ }^{10}$ Thus, a patient who is not informed of a mistake may feel angry and betrayed ${ }^{11}$; the patient may think that a privileged relationship has been violated. ${ }^{12}$

\section{Potential Harms of Disclosure to the Patient}

Patients may be harmed by learning that a mistake was made in their care. The knowledge may cause alarm, anxiety, and discouragement. It may destroy patients' faith and confidence in the physician's ability to help them. Patients may become disillusioned with the medical profession in general. This may cause them to decline beneficial treatments, or decrease their adherence to beneficial treatment regimens or habits. ${ }^{8}$

Not all patients want to know everything about their medical care. Some would rather not be burdened with the complexities of their illness. The well-meaning disclosure of potentially serious, but inconsequential mistakes may cause unwelcome confusion. In such cases, patients may feel they would be better off not knowing that a mistake had been made in their care. As the American College of Physicians Ethics Manual states, "society recognizes the 'therapeutic privilege,' which is an exemption from detailed disclosure when such disclosure has a high likelihood of causing serious and irreversible harm to the patient." However, the American College of Physicians offers the following caution: "On balance, this privilege should be interpreted narrowly; invoking it too broadly can undermine the entire concept of informed consent." 6

\section{Potential Benefits of Disclosure to the Physician}

The physician might also benefit from disclosing a mistake to the patient or family. The knowledge of making a mistake that harmed a patient can cause the physician to experience great emotional distress. ${ }^{3,8,13,14}$ The physi- 
cian may be relieved to admit the mistake. In the case of a serious mistake, the patient or family member may be the only person able to forgive the physician for making the mistake. This may be the only way for the physician to gain absolution for the mistake. ${ }^{13}$ Many patients appreciate the physician's honesty, and disclosure of a mistake actually may strengthen the doctor-patient relationship. For example, when one of the authors failed to obtain a serum ferritin test during the evaluation of a patient referred for an enlarged liver, the diagnosis of hemochromatosis was delayed significantly. When the patient was told about the omission, he responded, "That's O.K. After all, doctor, you can't think of everything."

Candid disclosure of a mistake may decrease the likelihood of legal liability. ${ }^{15}$ Some have suggested that a strong doctor-patient relationship makes patients less likely to bring suit. ${ }^{16}$ Furthermore, if the patient learns about a mistake and brings a lawsuit, failure to disclose may place the physician in greater jeopardy. ${ }^{17}$

Disclosing mistakes may help physicians to learn and improve their practice. ${ }^{18}$ In a survey by Quill and Williamson, responding physicians reported that sharing errors with colleagues, students, friends, and sometimes patients prevented isolation, and marked the beginning of grieving about and learning from the mistake. ${ }^{19}$ Admitting a mistake may also help the physician accept responsibility for it, and may help the physician make constructive changes in practice. ${ }^{3}$ Physicians may also learn vicariously from mistakes made by others, and be able to avoid making similar mistakes themselves.

\section{Potential Harms of Disclosure to the Physician}

Revealing a medical mistake to a patient is often difficult and painful for the physician. The patient may become angry and upset, and such reactions can be highly stressful to doctors. ${ }^{8}$

Many physicians fear that disclosing a serious medical mistake will expose them to the risk of a malpractice suit. If a lawsuit ensues, the physician may be subjected to increased malpractice premiums as well as psychological stress. ${ }^{20}$

Disclosure of a mistake may harm the physician through loss of referrals, hospital admitting privileges, preferred provider status, credentials, and even licensure. Selective contracting and physician profiling by managed care organizations create more tangible threats to the physician's livelihood. The development of the National Practitioner Data Bank ${ }^{21}$ adds the possibility that an incident will leave a permanent mark on the physician's record. Disclosure of mistakes may also damage the physician's reputation through the loss of respect or status among colleagues. In small communities, the physician's public reputation may also suffer.

Following disclosure of a serious error, the career of a physician-in-training may be harmed by poor evaluations or letters of recommendation, or even dismissal. Even without the expectation of overt punishment, it is difficult to admit wrongdoing.

A consequentialist argument for the disclosure of mistakes to patients would be framed in terms of the above-noted benefits and harms to individual patients and physicians. In the doctor-patient relationship, a physician is to act for the sake of the patient; therefore, in weighing the benefits and harms of disclosure, the benefits and harms to the patient should have greater weight than those to the physician. There are also duty-based grounds for holding that, in certain cases, a physician should disclose medical error to a patient. We now turn to such arguments.

\section{THE PHYSICIAN'S DUTIES}

In what follows, we argue that a physician's responsibility to disclose a mistake to a patient can be derived from the fiduciary character of the doctor-patient relationship (that is, the fact that this relationship is based on trust). ${ }^{22}$ The fiduciary character of this relationship can be further articulated in accordance with the principles of nonmaleficence, beneficence, respect for patient autonomy, and justice. ${ }^{23}$

Primum non nocere, "first, do no harm," states the principle of nonmaleficence: a caregiver has a grave responsibility to avoid harming the patient. ${ }^{24,25}$ The principle of beneficence enjoins physicians to act for the best interests of their patients' health even if the physician's own financial or professional well-being is not benefited by so acting. ${ }^{21}$ In cases in which harm resulting from a mistake can be reversed or ameliorated, the physician is obligated to do so. For example, if a sponge has been left in a patient after surgery, the sponge can be removed and infection can be prevented. In such cases, remedying or mitigating the harms caused by a mistake often requires the physician to disclose the mistake to the patient.

Respect for patient autonomy enjoins physicians to disclose a mistake that seriously harmed a patient. ${ }^{17}$ This is the case when full disclosure frees patients of mistaken beliefs concerning their past, present, or future medical conditions, thus enabling them to make informed decisions about future medical care. ${ }^{6,7}$ It may also be the case even if the patient does not need to know of the error in order to make future decisions about medical care. This is because patients have a claim to know their own history and to be free of mistaken beliefs concerning their past, present, or future medical condition. ${ }^{7,11}$ In short, a physician's obligation to respect patient autonomy indicates that a doctor has an ethical obligation to disclose mistakes to patients. ${ }^{7}$

When a nonremediable mistake has been made, the doctor may have an ethical duty to disclose it to the patient so that the patient can be compensated. Justice requires that people be given what is due to them. It would be unfair not to compensate a patient who was seriously harmed by mistake, e.g., for further medical care necessi- 
tated by the mistake, for income lost due to the mistake, for pain and suffering, or for loss of function. The more serious the harm and the greater the need of the patient for compensation, the greater the physician's responsibility to make amends.

Physicians may be less obligated or not obligated at all to disclose a mistake that had little marginal impact, such as a serious medication error involving a moribund patient or the failure to recognize a pneumothorax caused during a failed attempt at cardiopulmonary resuscitation. Although it can be argued that disclosure is discretionary in these cases, the counter-argument can be advanced that even these mistakes should generally be disclosed. The physician has little to lose by so doing. These cases may provide a good opportunity for open and honest discussion and may strengthen the relationship with the patient or family.

In summary, the fiduciary character of the doctorpatient relationship indicates that a physician has the ethical duty to disclose error to a patient when disclosure furthers the patient's health, respects the patient's autonomy, or enables the patient to be compensated for serious, irreparable harm.

\section{Practical Issues in Disclosure of Mistakes}

Accepting the physician's obligation to disclose mistakes, there are practical issues concerning whether, when, who, and how to tell about the mistake. For uncertain cases, who should decide whether or not to tell? Is there an ideal time to tell the patient? What should be done in the case of the incompetent patient? When more than one physician was involved, who should tell the patient? What should be the role of hospital quality assurance and risk management personnel?

Deciding Whether to Disclose a Mistake. In cases in which disclosing a mistake seems controversial, who should decide whether or not to tell? The individual physician is biased against disclosure, and can easily rationalize the decision not to tell. The burden of proof should be on the physician to justify not disclosing a mistake. However, the decision should not be left to the individual physician's judgment. It would be important to obtain a second opinion to represent what a reasonable physician would do and be willing to defend in public. This second opinion would be particularly important in cases in which there was an adverse outcome, and the physician is inclined not to tell. A formal body such as an institution's ethics committee or quality review board seems preferable to informal consultation with peers, who might be similarly reticent.

Timing of Disclosure. The timing of disclosure should be considered. Although the patient might benefit from learning about a mistake as soon as possible after it occurred, disclosure should be made at a time when the patient is physically and emotionally stable. For example, disclosure of a surgical error should be delayed, if possible, until the patient has recovered sufficiently to be able to understand and deal with the information.

Who Should Disclose the Mistake? When a mistake is made by a physician in training, responsibility is shared with the attending physician of record. It may be most appropriate for the attending physician and house officer to disclose the mistake to the patient together. ${ }^{14}$ Sometimes it may be appropriate to involve an institutional representative, such as a hospital administrator, risk manager, or quality assurance representative, in the disclosure.

The Incompetent Patient. Many patients with impaired decision-making capacity can still appreciate an apology. However, some patients lack the mental capacity to understand and appreciate what the physician tells them about medical errors, even if the discussion is simplified. There is no need to inform an incompetent patient. However, if there is a family member or other effective decision maker, this surrogate should be informed. The physician who will be taking care of the patient in the ambulatory setting should also be informed.

What to Say? Disclosure is often difficult, for several reasons. The facts of the case may be too complicated to be explained easily, and may not be known precisely. The physician may be tempted to frame the disclosure in a way that obscures that a mistake was made.

Disclosure of a mistake is an instance of "breaking bad news" to patients. ${ }^{26-29}$ There is need for medical education about conducting these discussions. The upsetting news that a mistake has occurred and information regarding the consequences should be presented to the patient in a way that minimizes distress. The American College of Physicians Ethics Manual offers the following guidance, which could be applied to the disclosure of a mistake: "Information should be given in terms the patient can understand. The physician should be sensitive to the patient's responses in setting the pace of disclosure. . . Disclosure should never be a mechanical or perfunctory process." ${ }^{6}$ The physician should recognize that patients or families may become upset or angry, and accept this as a natural response, taking care not to react defensively.

In telling the patient about an error, the physician should begin by stating simply that he or she has made a mistake. It may be helpful to describe the decisions that were made, including those in which the patient participated. The course of events should then be described in detail, using nontechnical language. The nature of the mistake, consequences, and corrective action taken or to be undertaken should be stated. The physician should then express personal regret and apologize for the mistake. Finally, the physician should elicit questions or concerns from the patient and address them.

The harm of disclosing a mistake may be minimized if disclosure is made promptly and openly, if apologies are 
offered, and if charges for associated care are forgone. When the mistake had a major adverse impact on the patient, an offer should be made to cancel charges for subsequent care needed to remedy the mistake and to provide the necessary supportive services.

Financial amends should include all extra expenses incurred, such as physician services, error-generated laboratory fees, hospital expenses, and drug costs. Hospital risk management teams sometimes adopt and malpractice insurers sometimes encourage such an approach, which may reduce the number and size of malpractice suits. The physician rarely if ever pays for any of these services out of pocket. Under capitated payment, the hospital or group absorbs the costs (if individual physicians are capitated for pharmacy services they may also share the costs). If health insurance is available to pay for medical care, a decision should be made whether or not to bill the insurer for the services. It can be argued that the insurance company bears some co-equal responsibility because it insures the patient for all outcomes. However, companies may want recourse to reclaim some of the money. In all cases, it is important that hospital administration and risk management be involved in decisions and negotiations about billing.

A physician who had prescribed a sulfonamide to a patient known to be allergic to sulfa, causing an anaphylactoid reaction, might say, "Mrs. Smith, I have discovered what has caused you to become so ill. I regret to say that I made a mistake. Before prescribing the medication for your infection, I failed to check whether you were allergic to it. You are. The itchy rash, joint pains, and fever you now have are due to the allergy. I am giving you ibuprofen and diphenhydramine to help you feel better, and I expect you will gradually improve over the next several days. I feel very badly that my not checking has caused you to have this reaction. I am sorry. Of course, there will be no charges for the antibiotic or the medications I am now prescribing to remedy my mistake. Do you have any questions for me?"

\section{Overcoming Barriers to Disclosure}

From a pragmatic point of view, physicians are often most concerned about the potentially harmful personal consequences of disclosing a mistake. In blunt terms, physicians may question whether any possible benefits to the patient are worth the possible risks of a lawsuit to their career or livelihood. This clash between ethical ideals and pragmatic reality is a difficult one. It may sound unconvincing to exhort physicians to do what is best for the patient. However, the AMA's Council on Ethical and Judicial Affairs states, "Concern regarding legal liability which might result following truthful disclosure should not affect the physician's honesty with a patient." 7

We would make several responses to physicians who hesitate to disclose mistakes that cause significant harm to patients because of fears of litigation. First, disclosing mistakes may reduce the risk of litigation, if patients appreciate physicians' honesty and fallibility. ${ }^{15}$ Second, serious mistakes may come to light, even if physicians do not disclose them. Patients may wonder about the cause of their changed condition, ask other caregivers, or even ask their physicians directly. Any perception that the physician tried to cover up a mistake might make a patient more angry and more litigious. ${ }^{17}$ Third, in disclosing mistakes physicians can take steps to mitigate any harms that may occur to them. Physicians can learn how to disclose mistakes in a manner that diffuses patient anger. Furthermore, when mistakes have caused serious harm to patients, physicians can take the initiative in recommending to institutional risk management personnel or malpractice insurers that a prompt and fair settlement is made out of court.

For an injured patient to obtain compensation through the tort system requires proof of negligence, defined as violation of professional standards. This creates an untenable conflict for physicians, for whom compensation to the patient demands the demonstration of malpractice. Acts of negligence constituted only a small proportion of the errors in the Harvard Medical Practice Study, ${ }^{1}$ and only a small proportion of injuries resulted in compensation for the patient. Thus, the current system obstructs detection and just compensation for errors and inhibits disclosure. The need to report and reduce errors constitutes a major ethical impetus for reform to a system of no-fault, nonadversarial patient compensation. Such a system would facilitate a move to a systems approach incorporating human factors research to reduce errors. ${ }^{2,30}$

The fear of damage to reputation and loss of respect from peers may also inhibit physicians from disclosing mistakes. To overcome this barrier will require increased recognition and acceptance of mistakes as part of clinical practice. Guidelines should be created to describe what physicians should do when they make a mistake. Such guidelines should also describe what to do when a colleague tells you about a mistake you have made or a mistake he or she has made. The importance of providing emotional support needs to be emphasized. It is particularly important to help physicians-in-training cope with their mistakes in such a way as to help them maintain their confidence and develop professionally. ${ }^{14}$

\section{Disclosure of Mistakes Made by Other Physicians}

A physician who, in the care of one of his or her own patients, learns of or witnesses a major error (e.g., a surgical mishap) made by another physician, has several options. These include waiting for the other physician to disclose the mistake, advising the other physician to disclose the mistake, arranging a joint meeting to discuss the mistake, or telling the patient directly. ${ }^{8}$ Insofar as the doctorpatient relationship obtains in such a case, physicians have an obligation to facilitate disclosure. However, they may be reluctant to say anything because of lack of defin- 
itive information, because of the thought that "there but for the grace of God go I," or because of fear of hurting the feelings of colleagues, or of straining professional relationships. Social norms militate against disclosing when a colleague makes a mistake. From an early age, we are socialized against "tattling” on our peers. In addition, physicians may fear that disclosure would lead to libel suits. Unfortunately, there are no guidelines describing the obligations of a physician who learns of a mistake made by another physician on his or her own patient.

The simplest solution is to leave the discussion up to the physician who made the mistake. However, there is no assurance that the patient actually will be informed. ${ }^{31}$ By advising the physician who erred to tell the patient, the observing physician may fulfill his or her responsibility for disclosure, but the patient also may not be informed. Simultaneously advising quality assurance or risk management personnel would increase the likelihood that the patient would be told. Arranging a joint conference with the patient and original physician would assure the observing physician that appropriate disclosure was made, while preserving the primacy of the relationship between the other physician and patient. These other options failing, one might tell the patient directly of the error. ${ }^{8}$ Although this conversation may be awkward and may interfere with the other physician's relationship with the patient, it does guarantee disclosure. Policy statements from medical staff offices and medical societies, as well as potential involvement by these bodies, are needed to guide and facilitate these difficult interactions.

\section{CONCLUSIONS}

Consideration of the doctor-patient relationship indicates that a physician has ethical obligations to disclose significant errors when disclosure benefits the health of the patient, respects the patient's autonomy, or is called for by justice. This is so even if such disclosure does not benefit the physician. Only in rare cases, when disclosure would threaten to undermine the patient's autonomy, or when the patient explicitly states a preference not to be told about such untoward events, should the physician not disclose the mistake. These same considerations suggest that a physician also has a considerable duty to ensure that disclosure occurs when, in the care of his or her own patient, another physician makes a serious mistake.

\section{REFERENCES}

1. Brennan TA, Leape LL, Laird N, et al. Incidence of adverse events and negligence in hospitalized patients: results of the Harvard Medical Practice Study II. N Engl J Med. 1991;324:370-6.
2. Leape LL. Error in medicine. JAMA. 1994;272:1851-7.

3. Wu AW, Folkman S, McPhee SJ, Lo B. Do house officers learn from their mistakes? JAMA. 1991;265:2089-94.

4. Christensen JF, Levinson W, Dunn PM. The heart of darkness: the impact of perceived mistakes on physicians. J Gen Intern Med. 1992;7:424-31.

5. American Medical Association. Principles of Medical Ethics; 1957: section 4

6. American College of Physicians. American College of Physicians Ethics Manual. 3rd ed. Ann Intern Med. 1992;117:947-60.

7. AMA Council on Ethical and Judicial Affairs and Southern Illinois University School of Law. Code of Medical Ethics, Annotated Current Opinions. Chicago, Ill: American Medical Association; 1994.

8. Lo B. Disclosing mistakes. In: Problems in Ethics. Baltimore, Md: Williams \& Wilkins; 1994:307-13.

9. Katz J. Why doctors don't disclose uncertainty. Hastings Center Rep. 1984:14:35-44.

10. Veatch RM. The principle of honesty. In: A Theory of Medical Ethics. New York, NY: Basic Books; 1981:214.

11. Vogel J, Delgado R. To tell the truth: physicians' duty to disclose medical mistakes. UCLA Law Rev. 1980;28:52-94.

12. Bok S. Lies to the sick and dying. In: Lying: Moral Choice in Public and Private Life. New York, NY: Vintage Books; 1979:232-55.

13. Hilfiker D. Facing our mistakes. N Engl J Med. 1984;310:118-22.

14. Wu AW, Folkman S, McPhee SJ, Lo B. How house officers cope with their mistakes: doing better but feeling worse? West $J$ Med. 1993; 159:565-9.

15. Gutheil TG, Bursztajn H, Brodsky A. Malpractice prevention through the sharing of uncertainty. Informed consent and the therapeutic alliance. N Engl J Med. 1984;311:49-51.

16. Levinson W. Patient-physician communication. A key to malpractice prevention. JAMA. 1994;272:1619-20. Editorial.

17. Robertson G. Fraudulent concealment and the duty to disclose medical mistakes. Alberta Law Rev. 1986;25:215-23.

18. Bosk CL. Forgive and Remember: Managing Medical Failure. Chicago, Ill: The University of Chicago Press; 1979.

19. Quill THE, Williamson PR. Health approaches to physician stress. Arch Intern Med. 1990;150:1857-61.

20. Martin CA, Wilson JF, Fiebelman ND 3d, Gurley DN, Miller TW. Physicians' psychologic reactions to malpractice litigation. South Med J. 1991;84(11):1300-4.

21. Oshel RE, Croft T, Rodak J Jr. The National Practitioner Data Bank: the first 4 years [see comments]. Public Health Rep. 1995; 110(4):383-94.

22. Pellegrino ED, Thomasma DC. For the Patient's Good: The Restoration of Beneficence in Health Care. New York, NY: Oxford University Press; 1988.

23. Beauchamp TL, Childress JF. Principles of Biomedical Ethics. New York, NY: Oxford University Press; 1994.

24. Hippocrates. Epidemics, vol. I, x, (translated by WHS Jones). Cambridge, Mass: Harvard University Press; 1939:165.

25. Nightingale F. Preface. In: Notes on Hospitals, 3rd ed. London, UK: Longman, Green, Longman, Roberts, \& Green; 1863:Iii.

26. Campbell ML. Breaking bad news to patients. JAMA. 1994;271:1052.

27. Davis H. Breaking bad news. Practitioner. 1991;235:522-6.

28. Girgis A, Sanson-Fisher RW. Breaking bad news: consensus guidelines for medical practitioners. J Clin Oncol. 1995;13(9):2449-56.

29. Relman AS. Telling patients 'the truth.' Physician's Management. November 1991:41-2;44.

30. Reason JT. Human Error. New York, NY: Cambridge University Press; 1990.

31. Paget MA. Your son is cured now; you may take him home. Cult Med Psychiatry. 1982:6:237-59. 